\title{
UNA EXPERIENCIA MALOGRADA: LA SOCIEDAD DE SOCORROS MUTUOS DEL CLERO (1847 - 1857)
}

\author{
JOSÉ ANTONIO VÁZQUEZ VILANOVA
}

\begin{abstract}
Resumen
A menudo, la historia encierra experiencias fallidas, episodios que de no ser por la labor del investigador, que las saca a la luz, permanecerían para siempre ignorados. Es el caso de la Sociedad de Socorros Mutuos del Clero. Su creación responde a la iniciativa de un grupo de sacerdotes dispuestos a encontrar soluciones a la difícil situación en que se hallaba sumido el clero, en lugar de lamentarse o añorar tiempos pasados, pero también al deseo de emulación, vistos los buenos resultados, de las asociaciones de trabajadores que en aquellos momentos habían empezado a constituirse en España. Sin embargo, su corta trayectoria parece hacer discurrido entre dificultades económicas y desacuerdos entre sus socios, que finalmente darán al traste con la Sociedad. Pese a esto, muchos clérigos hallaron en ella un socorro cuando más lo necesitaban. Su fracaso final evidencia, es cierto, la insolidaridad y la falta de unión de muchos de sus miembros, pero no oculta a los que respondieron positivamente y trataron de que la Sociedad continuase siendo una realidad.
\end{abstract}

\section{Palabras clave}

Clero, asociación, caridad, pensiones, Madrid, Santiago.

\begin{abstract}
Often, history contains bankrupt experiences, episodes that would remain forever unknown if the researcher's work would not bring them to light. This is the case of the Society of Mutual Aids of the Clergy. Its creation responds to the initiative of a group of priests willing to find solutions to the difficult situation in which the clergy was, instead of complaining or missing past times, but also with the emulation desire, seen the good results, of the associations of workers that had begun to be constituted in Spain at those moments. However, Its short trajectory seems to have gone between economic difficulties and disagreements among its partners that finally will ruin the Society. In spite of this, many clergymen found in it an aid when more they needed it. Its final failure evidences, it is certain, the lack of solidarity and the lack of union of many of its members, but it does not hide those that responded positively and tried that the Society continued being a reality.
\end{abstract}

\section{Keywords}

Clergy, association, charity, pensions, Madrid, Santiago. 


\section{INTRODUCCIÓN}

Hasta que, al calor de la Revolución de 1.868, aparezcan los primeros sindicatos propiamente dichos, las llamadas sociedades de resistencia, el movimiento obrero se canalizará exclusivamente a través de las Sociedades de Socorros Mutuos. Hasta entonces, serán las únicas sociedades obreras existentes en España, y bien podemos considerarlas los verdaderos embriones de los sindicatos. Se trata de asociaciones de trabajadores cuya finalidad es el socorro mutuo entre sus miembros en caso de enfermedad, paro, inutilidad, gastos de entierro o incluso de enseñanza. Parece ser que su aparición se remonta ya al siglo XVI, si bien su despegue no tendrá lugar hasta el siglo XVIII. Pero será sobre todo a partir de la Real Orden de febrero de 1839, en la cual se fomentaba la creación de este tipo de asociaciones. Se autorizaba la asociación obrera bajo la forma de sociedades de socorros mutuos, reprimiendo al mismo tiempo otro tipo de sociedades de carácter más reivindicativo. Es por ello que la lucha obrera durante largo tiempo se canalizará a través de este tipo de asociaciones, que permitían la cobertura legal necesaria para las actividades de estas primeras asociaciones de trabajadores. De hecho, en 1853 el gobierno disolverá estas sociedades. Sin embargo, en mayo del año siguiente se volverán a permitir las sociedades de socorros mutuos, pero de nuevo, en abril de 1857, volverán a abolirse todas las sociedades obreras del tipo que sean. Más tarde, volverán a permitirse, pero sometidas a un estrecho control ${ }^{1}$.

En Santiago la primera sociedad de socorros mutuos de tipo profesional es la Sociedad de socorros mutuos de profesores del arte de vestir, creada en 1847. Dos años más tarde, en 1849, se crearán otras dos, la Sociedad de socorros mutuos de empleados civiles, y la Sociedad de socorros mutuos artística e industrial. Las restantes sociedades de la ciudad se crearán a partir de mediados de la década de 1850.

Como los mismos fundadores reconocen, la Sociedad de socorros mutuos del Clero surge siguiendo el ejemplo de las sociedades de otros oficios que han empezado a constituirse en España. Sus propios estatutos están inspirados en los de estas primeras asociaciones de trabajadores. Se trata de un fenómeno sin precedentes, y también sin continuidad en el tiempo. Podemos incluso considerarla la primera asociación profesional del clero propiamente dicha. Hasta entonces, en cuanto grupo social o profesional, las formas asociativas del clero se habían reducido a cofradías, como la de Nuestra Señora de la Concepción, fundada ya en el siglo XV y que agrupaba a buena parte del clero de la ciudad de Santiago; o aquella otra fundada

\footnotetext{
${ }^{1}$ Herminia Pernas Oroza, "O asociacionismo obreiro en Santiago de Compostela: unha aproximación ás sociedades benéficas". En Historia Nova II. Contribución dos Xoves Historiadores de Galicia. Pp. 137-156.
} 
en el siglo XVI, con sede en la parroquia de San Félix de Quión, municipio de Touro, y que comprendía el clero de los arciprestazgos de Ferreiros, Bama, Bembexo y Ridadulla. Sin embargo, difícilmente podríamos considerar a aquellas cofradías de clérigos como asociaciones profesionales en el sentido estricto del término. Los fines de estas cofradías no eran asistenciales, y menos aún de defensa mutua ${ }^{2}$.

De ahí la originalidad y lo insólito de esta iniciativa; más aún entre el clero, tan poco propenso a este tipo de cuestiones. Aquí radica el interés de la presente investigación, y uno de los motivos para llevarla a cabo ${ }^{3}$. Como siempre, las principales dificultades para la investigación histórica derivan de la escasez de las fuentes conservadas. Esto también puede aplicarse al presente estudio. Sin embargo, se han conservado cuatro carpetas, depositadas en el Archivo Histórico Diocesano de Santiago, entre los fondos procedentes de San Martín Pinario, que con las inevitables lagunas nos permiten conocer tanto el carácter y funcionamiento de la Sociedad a nivel general como seguir con más detalle la trayectoria particular de la Comisión instalada al efecto en la diócesis compostelana. Sobre esta base, dividiremos nuestro estudio en dos apartados. El primero estará dedicado a conocer la organización y funcionamiento de la Asociación en su conjunto, mientras que la segunda abarcará un estudio más detallado de la comisión establecida en Santiago.

\section{LA SOCIEDAD DE SOCORROS MUTUOS DEL CLERO ${ }^{4}$}

La iniciativa parece haber partido de D. Félix Lázaro García, sacerdote residente en Madrid, quien también llevará a cabo la primera redacción de los estatutos. Junto a otros compañeros, todos ellos presbíteros vecinos de Madrid, constituirá el 12 de julio de 1846 una Junta Creadora para llevar a efecto la nueva Sociedad. En esta Junta provisional será elegido presidente D. Juan Miguel Ximena, secretario D. Félix Lázaro García y tesorero D. Juan de Dios Carranza. De su seno saldrá una comisión encargada de examinar y revisar los estatutos, formada por D. Juan

\footnotetext{
${ }^{2}$ Los beneficios que recibían sus miembros eran básicamente de tipo espiritual: asistencia al entierro, funerales, misas y oraciones por el alma de los cofrades vivos y difuntos. Los beneficios materiales se reducían a la participación de los cofrades en los ingresos y en las rentas de la cofradía.

${ }^{3}$ Aparte de esto, está la virginidad de un tema que no parece cuente con estudios previos. Su andadura en el tiempo fue breve y da la impresión de haber pasado sin dejar apenas rastro, como una experiencia truncada que fuese preciso olvidar cuanto antes. Esto todavía contribuye a excitar más nuestra curiosidad.

${ }^{4}$ A partir de este momento, a menos que se indique otra cosa, las fuentes archivísticas utilizadas, tanto para la Sociedad de Socorros Mutuos del Clero como para la comisión establecida en Santiago, corresponden al Archivo Histórico Diocesano de Santiago, Fondo San Martín Pinario, Serie San Martín, Legajos 91, 97, 98 y 99.
} 
Miguel Ximena, D. Atilano Melquizo, D. Francisco Mazon de Solares y D. Félix Lázaro García. El 2 de agosto de 1846 la comisión presentó dichos estatutos en Junta general, siendo aprobados por unanimidad. Tras haber sido aprobada la iniciativa por la diócesis de Toledo, el 27 de octubre de ese año Isabel II aprobaba la creación de la Sociedad y sus estatutos, siendo confirmada por Real Cédula el 31 de enero de 1847 mandando además se publicasen los citados estatutos.

Los motivos que les inducen a dar vida a la nueva asociación parecen evidentes. En aquellos momentos, la situación económica del clero era muy precaria. Las desamortizaciones los habían privado de sus fuentes de ingresos, mientras que la dotación de culto y clero, concebida como indemnización que el Estado debía hacer a la Iglesia, pese a quedar recogida en el convenio entre la Santa Sede y la reina de España de 1845, no se llevaría a efecto hasta el Concordato de 1851. En este sentido, el 8 de junio de 1846, en una reunión de sacerdotes con motivo de unas conferencias morales, D. Félix Lázaro pronunció un discurso donde, además de dar a conocer los futuros estatutos de la Sociedad, se refería claramente a la necesidad de una institución como ésta. Hasta ahora, el clero siempre había practicado la caridad con los demás, pero en el momento presente "hemos quedado reducidos á la estrechez, á la miseria, á mendigar el sustento de las mismas manos á quienes hemos socorrido". De nada sirve buscar las causas de esta situación; es preciso, una vez pasado el desconcierto inicial, recobrar la calma y encontrar soluciones. Y para hallar el remedio "una cosa nos queda que no nos ha podido quitar el infortunio ni todas las privaciones. Tenemos aun un tesoro que no está al alcance de los ladrones, que no consume el tiempo ni roe la polilla (...) La caridad, señores, la caridad que ha sido siempre el distintivo y ha estado identificada con nuestra clase; la caridad que hemos ejercido con todos los hombres en nuestra abundancia y que ahora es preciso que la ejerzamos entre nosotros mismos". Pero los socorros aislados son insuficientes, y por ello "unámonos y formemos un cuerpo compacto, ordenemos la caridad entre nosotros (...) Establezcamos entre nosotros un orden de caridad mútua y contínua, pongamos los cimientos á esta obra (...) á que se acogerán los desgraciados sin el embarazo y el pudor que causa la pobreza". Pero también, y esto es lo más llamativo, está el deseo de emulación de lo que han empezado a hacer los trabajadores, y más cuando se han palpado los beneficios y utilidades que trae consigo ${ }^{5}$.

\footnotetext{
${ }^{5}$ Así lo afirma D. Félix Lázaro García, con estas palabras: "Después que han planteado (...) esta institución los profesores de medicina, cirujía y farmacia, los de veterinaria, los empleados, los comerciantes, hacendados y propietarios, y hasta las clases pobres de la Sociedad (...) ¿En qué consiste que habiéndose estendido tanto y palpado sus utilidades y ventajas no se haya adoptado por el Clero, clase á cuyos individuos unen vínculos, obligaciones y motivos mas poderosos, mas estrechos, mas caritativos y mas santos?".
} 
El carácter, organización y objetivos de la Sociedad aparecen claramente establecidos en los estatutos de 1846. Unos estatutos que serán substancialmente modificados en algunos de sus puntos en febrero de 1849.

Puesta bajo la protección del Apóstol San Pedro, la Sociedad está pensada para todos los presbíteros seculares y regulares exclaustrados de España, siempre y cuando estén habilitados para ejercer el ministerio sacerdotal y no padezcan achaque o dolencia alguna habitual de consideración 6 , además de solicitar su ingreso y cumplir con las obligaciones recogidas en los estatutos. Pero además, en 1846 se establece que durante los seis primeros meses de vida de la Asociación, por ser considerados socios fundadores, serán admitidos los sacerdotes cualquiera que sea su edad, pero pasado ese tiempo no serán admitidos los que pasen de 50 años ${ }^{7}$. En 1849, los límites de edad serán anulados.

El gobierno de la Sociedad estará a cargo de una Junta Directiva en Madrid, y de las Comisiones subalternas que se establecerán en las capitales de las diócesis y en otros puntos si fuese necesario ${ }^{8}$. Esta Junta Directiva será el órgano supremo, y en un primer momento se compondrá de 10 socios nombrados todos ellos en Junta general. Serán un presidente, un vicepresidente, un secretario, un vicesecretario, un contador, un vicecontador, un tesorero, un vicetesorero y dos vocales. Más tarde, con la reforma, pasarán a ser 15 sus miembros, al haber dos vicepresidentes y pasar los vocales de dos a seis miembros. Estos cargos durarán tres años, y serán elegidos de mayor a menor atendiendo a la importancia de los mismos. Pero este funcionamiento democrático quedará limitado en 1849 , tal vez debido a una necesidad de control por parte de la jerarquía. Su máximo dirigente ya no podrá ser elegido en Junta general entre cualquiera de los socios, sino que el presidente de la Junta Directiva será siempre alguno de los prelados residentes en Madrid o en su defecto otro eclesiástico constituido en alta dignidad, eso sí, con la condición de que sea socio. Además, los poderes del presidente se ven aumentados.

\footnotetext{
${ }^{6}$ En 1849 se acepta que los sacerdotes que por sus achaques o enfermedades habituales no pudiesen ingresar en la Sociedad, puedan hacerlo teniendo derecho a los beneficios espirituales, pero renunciando a toda pensión.

${ }^{7}$ Para tener una idea de lo abusivo de esta norma baste mencionar que en 1845 el clero de la ciudad de Santiago tenía una media de edad de 49 años. Esto nos muestra el gran porcentaje de clérigos que, a menos que se apresurasen para ingresar como miembros fundadores, quedarían al margen de la Sociedad, sin ningún tipo de socorros. Peor todavía si nos detenemos en determinados grupos. Así, los exclaustrados en ese año tenía una edad media de 55 años, y los párrocos de 57. Tal vez en estos primeros años, para consolidar la nueva Organización, era preciso obtener los mayores ingresos y recortar al mínimo los gastos. De ahí unas normas difíciles de entender en otras circunstancias. Además, de esta forma se lograría que la Sociedad creciese rápidamente.

${ }^{8}$ En 1849 se cambiará el nombre de subalternas por el de Comisiones Auxiliares por considerarlo más decoroso a las mismas.
} 
La Junta Directiva decidirá la admisión de socios y, llegado el caso, la expulsión de los mismos, cuidará de la recaudación e inversión de los fondos, velando sobre el pago de las pensiones y no permitiendo otros gastos que los necesarios. Igualmente, formará un presupuesto anual así como una cuenta general de los ingresos y gastos de todas las comisiones subalternas. También recibirá las quejas que le transmitan las comisiones o cualquier socio, tomando las medidas oportunas, y podrá suspender del cargo a cualquier miembro de las comisiones o de la Junta Directiva9 ${ }^{9}$.

Por su parte, las Comisiones subalternas o auxiliares se compondrán al principio de 7 miembros elegidos por una Junta general ordinaria de socios de la diócesis. Serán un presidente, vicepresidente, secretario, contador, tesorero y dos vocales. Luego pasarán a ser 10 los miembros, con un vicesecretario y 4 vocales. También se nombrarán dos visitadores para la capital de la diócesis, y otro para cada Arciprestazgo si fuese necesario. Los visitadores se informarán de los socios que en sus respectivos territorios hubiese enfermos o en cualquier apuro y les prestará, en nombre de la Sociedad, la ayuda que corresponda.

El centralismo, tan en boga en aquel momento, también vertebrará la organización de esta Sociedad. Las comisiones apenas podrán tomar resolución alguna por sí solas y estarán en todo subordinadas a la Junta Directiva, de quien recibirán las órdenes oportunas y a quien rendirán cuentas en todo momento ${ }^{10}$.

Por su parte, los fondos de la Sociedad están formados por los siguientes tipos de ingresos:

$1^{\circ}$ - En las cuotas de las acciones que tomen los socios. Cada socio tomará un número de acciones, que no podrán pasar de diez. Cada acción le dará

\footnotetext{
${ }^{9}$ Asimismo, cada año habrá dos Juntas generales ordinarias, que se celebrarán en Madrid y a las que podrá asistir cualquier socio sin necesidad de aviso.

10 Tenemos constancia, al menos, de dos movimientos separatistas. En noviembre de 1849 la Comisión Auxiliar de Segorbe acordó romper toda comunicación y dependencia respecto a la Junta Directiva de la Sociedad. La Junta reaccionó solicitando al jefe político de Castellón la disolución de la citada comisión. Este accedió a disolverla "porque de ninguna manera puede reconocerse su existencia legal, desde que ha querido proceder con independencia de la Sociedad general de que era auxiliar", encargándole al alcalde de Segorbe procediese a dicha disolución. Los miembros de la comisión aceptaron la disolución sin oponer resistencia.

Poco después, la comisión de Olvera también comunicaba su separación de la Junta Directiva. Como había hecho antes, la Junta pidió su disolución al jefe político de Cádiz. Sin embargo, los de Olvera debieron reconsiderar su decisión, por cuanto la Junta comunicaba al jefe político que "no siendo tan explícita su separación como la de Segorbe" de momento suspendiese todo procedimiento contra ella.

Estas medidas fueron justificadas por la Junta al asegurar que "llena de amargura se ha visto precisada á recurrir a la autoridad para hacer respetar sus determinaciones, lo que jamás haria, si á ello no se viese precisada para conservar la UNION de la Sociedad, sin la que es imposible llegar al grado de esplendor y estabilidad á que es llamada, y si no se hubiese desconocido su autoridad".
} 
derecho a dos reales diarios en caso de imposibilidad. Las cuotas variarán con la reforma de 1.849; la penosa situación del clero hacían necesaria una rebaja en las mismas ${ }^{11}$.

$2^{\circ}$ - En el importe de los dividendos que fuese necesario practicar. Cuando los demás ingresos no bastasen para cubrir los gastos de la Sociedad, se repartirá la cantidad que falte entre todas las acciones por igual. La cantidad que a cada socio le tocase pagar es lo que se llama dividendo. Para este reparto, únicamente se tendrá en cuenta el número de acciones, y no el valor de las mismas.

$3^{\circ}$ - En el producto de la venta de Estatutos y títulos. En 1.846 se especifica que cada socio está obligado a tener los estatutos de la Sociedad, cuyo importe abonará al recibirlos ${ }^{12}$. Entre los títulos, se incluyen los gastos de admisión que cada candidato deberá abonar para ser nombrado socio.

$4^{\circ}$ - En las donaciones que hubiere.

Apartado importante es el referido a las prestaciones a que tienen derecho los socios. Pueden ser tanto socorros espirituales como pensiones. Así, los socios enfermos o imposibilitados para ejercer el ministerio serán visitados y consolados; la Sociedad se encargará de que sean sustituidos en sus tareas. Igualmente serán asistidos en sus enfermedades, velándolos día y noche, sumunistrándoles o cuidando de que se les suministren todos los auxilios espirituales. Asistirán a su entierro la totalidad de los socios de la población donde hubiesen fallecido, y si alguno fuese tan pobre que no pudiese costear su entierro, la Sociedad correrá con los gastos. Asimismo, todos los años se celebrará un oficio por los socios difuntos, estan-

11 Durante los seis primeros meses de vida de la Sociedad cada socio, sin distinción de edades, tenía que pagar por cada acción 60 reales. Concluido este plazo, la cuota a pagar dependía de las edades de cada socio, tal como mostramos a continuación:

$\begin{array}{llrc}\text { Hasta los } 30 \text { años } & - & 60 & \text { reales por acción } \\ \text { De } 30 \text { a } 35 \text { años } & - & 80 & \text { “ } \\ \text { De } 35 \text { a } 40 \text { años } & - & 160 & \text { “ } \\ \text { De } 40 \text { a } 45 \text { años } & - & 300 & \text { “ } \\ \text { De } 45 \text { a } 50 \text { años } & -480 & \text { “ }\end{array}$

Por su parte, a partir de 1.849 las cuotas sufrirán una notable reducción, quedando de la siguiente manera:

Hasta los 30 años - 60 reales por acción

De 30 a 35 años - $80 \quad$ “

De 35 a 40 años - 100 “

De 40 a 50 años - 150 “

De 50 a 55 años - 270 “

De 55 en adelante - 300 “

$12 \mathrm{Su}$ precio era de 8 reales por ejemplar. 
do además todos los socios obligados a aplicar cada año una misa por todos sus compañeros difuntos ${ }^{13}$.

Aquellos socios que no puedan ejercer el ministerio sacerdotal tendrán derecho a una pensión de dos reales diarios por cada acción que tengan durante todo el tiempo que dure su imposibilidad ${ }^{14}$. Se entenderá por imposibilidad física cuando el socio padezca alguna enfermedad o accidente que le impida celebrar misa, y por imposibilidad moral cuando por cualquier causa se le privase de ejercer su ministerio o estuviese en circunstancias de no poder ejercerlo, ya sea suspenso, encarcelado o desterrado. Con la reforma de 1849 se aclara que, en caso de tener suspensas sus licencias, percibirá su pensión a menos que permanezca voluntariamente en la suspensión o, dicho de otro modo, cuando estando dispuesto el prelado a levantar la suspensión, el súbdito rehuse aceptar las condiciones exigidas. Ahora bien, si el socio tiene razones justas para no ceder a lo que se le pide, entonces será lo mismo que si el prelado no quisiese alzar la suspensión, y el socio tendrá derecho a seguir percibiendo la pensión. Esto último causó un cierto escándalo entre los más celosos defensores de las atribuciones episcopales ${ }^{15}$.

Al fallecer un socio, sus familiares pasarán a percibir su pensión, teniendo derecho preferente el padre y la madre ${ }^{16}$. Esta pensión se dará a una sola persona a excepción de los padres, que la gozarán conjuntamente, y la percibirán en caso de imposibilidad física, enfermedad, ancianidad o extremada pobreza. Sin embargo, estas pensiones tendrán una vida muy corta, siendo eliminadas con la reforma de 1849. En lugar de las mismas, todo socio tendrá derecho a disponer de 120 reales por acción en favor de la persona u objeto que disponga en su testamento. Si falleciese sin hacer testamento, se le entregará a los padres o hermanos del difunto, y si no los tuviese, se invertirá la mitad en sufragios por su alma, y la otra mitad quedará a beneficio de la Sociedad. Por extrema necesidad u otras causas,

\footnotetext{
${ }^{13}$ En 1.849 serán tres las misas a aplicar.

${ }^{14}$ Para ser tenida en cuenta, deberá pasar de 8 días.

${ }^{15}$ De subversivo lo tachó D. Fernando Charlín, uno de los visitadores, quien en una circular dirigida a la comisión de Santiago el 12 de septiembre de 1849 aseguraba que establece "un precedente de no mui sana doctrina (...) y he aquí como los subditos juzgan de las providencias de sus superiores (...) semejante precedente es subversivo de las atribuciones que el Sto Concilio de Trento da á los Ordinarios en sus Diocesis respectivas".

${ }^{16}$ En defecto de los padres, la pensión pasaría, por este orden, a los hermanos, sobrinos y criados. Sin embargo, en una circular de septiembre de 1848, la Junta asegura no tener reparos en la que la pensión se extienda a los padres y hermanos del socio difunto, pero no que se extienda a los sobrinos y criados, ya que esto podría llevar a la Sociedad a su ruina. Lo cual hace necesario abrir una discusión al respecto.
} 
el socio podrá ceder en vida este derecho a otra persona ${ }^{17}$. El último acto tendrá lugar en diciembre de 1849, cuando la Junta acuerde suprimir el derecho de los asociados a disponer de los 120 reales; a partir de ese momento, con la muerte del socio morirán también todos sus derechos y, al decir del obispo de Ourense, de este modo "la Sociedad se vé libre de un peso que amenazaba su ruina". Sin embargo, no todos opinaban así. Lo exiguo de las cantidades a percibir por los familiares primero, y la completa desarticulación del sistema poco después, tratándose de unos socorros tan necesarios en algunos casos, provocó descontento y disgusto entre un buen número de socios, como tendremos ocasión de comprobar más adelante.

Sobre la marcha de la Sociedad, al promulgarse la reforma de los estatutos en 1849, según datos facilitados por la Junta Directiva, ésta contaba con 12.427 socios, con 84 comisiones más 16 comisionados $^{18}$. Entre los socios, estaban los arzobispos de Toledo, Valencia y Tarragona ${ }^{19}$, además de 12 obispos $^{20}$ y el Patriarca de las Indias. Por su parte, en diciembre de 1850 Pío IX otorgó una serie de indulgencias a los miembros de la Sociedad, que se extendían a los socios difuntos. Contaba además la Sociedad con su propio periódico, El Clero Español. Las dificultades económicas obligaron a suspender su publicación desde el 1 de abril de 1852. Volverá

${ }^{17}$ Para revisar los estatutos de 1846, en enero de 1849 se nombró una comisión compuesta por cinco miembros. Uno de ellos, D. Camilo Mojón y Lloves, dirigió una carta al secretario de la comisión de Santiago informándole de las reformas que pensaban llevar a cabo y pidiendo al mismo tiempo su opinión al respecto. Así sabemos cual fue la intención primera al llevar a cabo algunos de los cambios. Para el caso que nos ocupa, en un principio se pretendía que los socios pudiesen disponer a favor de quien quisiesen a la hora de su muerte de 400 reales por acción. Vemos pues cómo al final esta cantidad fue rebajada considerablemente.

18 Sabiendo que en ese año había 60 diócesis en España (con el Concordato de 1851 quedarán reducidas a 55), tenemos una media de 207 socios por diócesis. Asimismo, tenemos un promedio de 148 miembros por comisión. Resulta muy difícil afirmar si estas cifras reflejan el éxito o el fracaso de la Sociedad en sus primeros años de vida. Cierto que en términos absolutos estaba lejos de contar con el apoyo mayoritario del clero español, pero dado el carácter de la Asociación y las reticencias de muchos ante este tipo de iniciativas, así como el hecho de partir de cero en una empresa semejante, las cifras reflejan un desarrollo más que notable.

${ }^{19}$ A los miembros de la Junta parece habérseles pasado por alto, pero lo cierto es que entre los socios también se contaba el arzobispo de Santiago Fray Rafael de Vélez. En la secretaría de la comisión de Santiago se conservaba, en un marco protegido con un cristal, su título de socio. Sin embargo, es posible que su ingreso fuese posterior al recuento que nos ocupa.

Más que por necesidad, probablemente los prelados se sumasen a la Sociedad para dar ejemplo a sus sacerdotes y animarles a inscribirse en la misma. También pudiera, de alguna forma, responder a una necesidad de control por parte de los obispos, y así evitar que la Asociación acabara transformándose en una plataforma de defensa del clero medio y bajo, incluso frente a los propios obispos.

${ }^{20}$ Entre los gallegos, la Junta únicamente menciona al obispo de Ourense, D. Pedro Zarandía y Endara, presidente al mismo tiempo de la comisión establecida en su diócesis. 
a aparecer con otro nombre, El Corresponsal Eclesiástico. Editado en Madrid y adoptado por la Junta como órgano oficial de la Sociedad, contiene las órdenes de la Junta, estado, cuentas y todo lo concerniente a la misma, además de artículos sobre literatura e historia ${ }^{21}$.

Desde el primer momento, tampoco faltaron los problemas y conflictos. Desacuerdos con la Junta Directiva motivaron que en 1848 fuera cesado el secretario y uno de sus principales artífices, D. Félix Lázaro; poco después el presidente también era obligado a dimitir. Esta decisión fue justificada en nombre de los intereses de la Sociedad. Tras esto, será nombrado presidente el arzobispo de Toledo, D. Juan José Bonel y Orbe. Los derechos preferentes del Primado a la presidencia quedarán confirmados con los nuevos estatutos de 1849. También hubo problemas entre la Junta Directiva y las comisiones. En abril de 1852 la Junta se queja de que algunas comisiones se niegan a remitir su estado y cuentas a la Sociedad, lo que imposibilita la formación del estado general de la Sociedad ${ }^{22}$. Esta situación motivó la apremiante circular dirigida en noviembre de ese año. Parte de las comisiones seguían sin remitir sus cuentas, al tiempo que la Junta se estaba viendo recriminada por algunas comisiones, amenazándola con la apostasía y deserción de muchos de sus miembros "en quienes reina el disgusto y descontento porque presagian su ruina y estincion”. Además, un gran número de socios no cumplen con sus obligaciones en los pagos, y cada uno "se cree con derecho á propalar contra ella las ideas y espresiones mas denigrantes y subversivas" 23 . La circular termina con un desesperado llamamiento a las comisiones para salvar la Sociedad. Se hace preciso que las órdenes de la Junta sean respetadas de una vez por todas; de esta manera "lejos de que se realizen jamás los infundados temores de aquellos, que disgustados por resentimientos particulares ó por dar oidos á la maledicencia de algunos, de quienes se vale el infierno como de instrumentos para que desacrediten con sus lenguas tan benéfica institucion y destruyan así un edificio tan conforme á la letra del Evangelio, ó de otros, que

${ }^{21}$ También incluye información sobre vacantes de dignidades en las catedrales junto con las convocatorias para las correspondientes oposiciones. Por su parte, desde el 1 de enero de 1854 incluirá también ocho páginas dedicadas a la historia y legislación eclesiásticas. El precio de la suscripción era de 10 reales en Madrid y de 12 en los restantes puntos por cada tres meses.

${ }^{22}$ Concretamente, de las 93 comisiones auxiliares, habían incumplido 27. Parece que una de las morosas era la comisión de Santiago.

${ }^{23}$ Parece que parte del descontento de algunas comisiones se debe a que la Junta no ha dado cuenta del estado de la Sociedad, cosa difícil si no le facilitan los datos las comisiones auxiliares, ni había acordado todavía la traslación de caudales, necesaria para ayudar a las más pobres, también debido según la Junta al desconocimiento de la situación de aquellas comisiones que todavía no le han remitido los datos precisos. 
creyéndose engañados por no haber reportado lucro alguno visible de las cantidades de que se han desprendido á favor de sus hermanos y compañeros en el ministerio Sacerdotal, pretenden inculcar en el alma de los buenos el descontento (...) dándole el colorido de disolucion; lejos repito de que los tales consigan su intento, se consolidará mas y mas la Sociedad, y podremos dar un solemne mentís á cuantos se declaran sus acérrimos enemigos". Como vemos, la palabra disolución llevaba largo tiempo pronunciándose. Lo cierto es que la morosidad de muchos de sus miembros junto con la negativa de algunas comisiones a rendir cuentas de su gestión serán problemas constantes, y darán lugar a una escasez de capitales que acabará dando al traste con la Sociedad ${ }^{24}$. Es preciso reconocer, en honor a la verdad, que las fuentes no nos permiten conocer a ciencia cierta las circunstancias concretas de su desaparición, aunque es probable que el decreto gubernamental de 1857 haya actuado como el golpe de gracia, lo mismo que aconteció con las demás asociaciones. Sin embargo, éstas se reconstituyeron. En cambio, la Sociedad de socorros mutuos del clero llevaba tiempo vegetando, quedando finalmente relegada, como una experiencia frustrada, al baúl de los recuerdos. Puede que la relativa mejoría de la situación económica del clero no hiciese tan necesaria la Sociedad, si bien las prestaciones que ésta ofrecía resultaban difícilmente prescindibles en una época en que los seguros sociales todavía no eran una realidad. Por otra parte, la mejoría afectaría a una parte del clero, los más beneficiados con las disposiciones del Concordato, frente a los que continuaban en una precaria situación ${ }^{25}$.

${ }^{24}$ El obispo de Ourense y presidente de la comisión de su diócesis proponía medidas extremas para salvar la situación. Concretamente, era partidario de que aquellos que faltasen a sus deberes con la Sociedad fuesen castigados con multas, e igualmente instaba a la Junta para que los que, voluntariamente o por la fuerza, se separasen de la Sociedad fuesen obligados a devolver todos los socorros que hubiesen recibido "que á no ser así, en los unos, socorridos, el separarse fuera especulacion detestable, y en los otros, separados, un premio escandaloso en vez de un castigo merecido: asi la arbitrariedad y el desorden harian inevitable su disolucion".

${ }^{25}$ El Concordato de 1851 no contribuyó a un reparto más equitativo de los ingresos; antes al contrario, ahonda en los contrastes dentro del clero, como puede comprobarse al constatar las enormes diferencias de dotación entre los distintos grupos. Tampoco variará la situación de los patrimonialistas. Para aquellos que no tienen beneficio, y que únicamente subsisten gracias a las limosnas de misas y al modesto patrimonio que sus padres hubieron de constituir a su favor para que pudieran ordenarse, no se contempla dotación alguna. 


\section{LA COMISIÓN AUXILIAR DE SANTIAGO}

La comisión de Santiago fue creada el 4 de enero de $1848^{26}$. Su instalación había sido previamente solicitada por escrito a la Junta Directiva, vistos los buenos resultados que estaba dando en otras zonas "pues la esperiencia acreditó en toda la España, que mil infelices hallaron en ella un asilo para librarse de la miseria, en que todos nos hallamos sumidos". Se nombró una primera comisión, compuesta por el presidente D. Ramón Francisco Caamaño; D. Juan Fontenla, vicepresidente; D. Remigio González Rey, secretario; D. Juan Rey Vázquez, tesorero; D. Florencio Insúa Ríomayor, contador. Todos ellos residían en la propia ciudad de Santiago ${ }^{27}$. Sin duda, el hecho de que la sede de la comisión estuviese en la ciudad del Apóstol reforzaba este protagonismo. La misma procedencia se constata en los sucesivos presidentes. Sería el caso de D. Evaristo Álvarez, racionero de la Catedral; D. Juan Fontenla, el anterior vicepresidente; D. Pedro de Jesús Caneda, párroco de Santa María de Sar, o D. Ramón Palacio, canónigo y maestro de capilla en la Catedral, que será su último presidente. Lo mismo podemos decir de los restantes miembros de las sucesivas comisiones. Este protagonismo del clero urbano de Santiago queda reforzado al comprobar que en 1848 el 53`52 \% de los socios eran vecinos de Santiago, mientras que en 1850 lo eran el $45^{\prime} 31 \%^{28}$.

En cuanto a la marcha de la Sociedad, ésta puede ser seguida, en primer lugar, a través de la evolución del número de socios y de sus acciones respectivas:

$\begin{array}{lccc}\text { AÑOS } & \mathrm{N}^{\circ} \text { SOCIOS } & \mathrm{N}^{\circ} \text { ACCIONES } & \text { MEDIA }^{29} \\ 1848 \text { (julio) } & 160 & 627 & 3^{\prime} 91 \\ 1848 \text { (diciembre) } & 213 & & \\ 1849 & 267 & 977 & 3^{\prime} 65 \\ 1850 & 282 & 1.036 & 3^{\prime} 67 \\ 1851 & 266 & 972 & 3^{\prime} 65 \\ 1853 & 145 & & \\ 1854 & 86 ? & & \end{array}$

\footnotetext{
${ }^{26}$ En un principio, tendrían la consideración de socios fundadores los que se inscribieran en los 15 días siguientes a su fundación. Pero viendo que el tiempo era tan escaso, y espoleados por las lógicas quejas, la comisión solicitó a la Junta la ampliación del plazo. Esta accedió, acordando fuesen tres meses a contar desde el 1 de octubre de ese año.

${ }^{27}$ El presidente y el secretario eran párrocos de la ciudad, el vicepresidente religioso exclaustrado, mientras que el tesorero y contador eran patrimonialistas.

${ }^{28}$ De hecho, hasta un $73 \%$ del clero de Santiago (secular y exclaustrados) podría, en sus años de mayor bonanza, haber pertenecido a la Sociedad.

${ }^{29}$ Este apartado se refiere al número medio de acciones por cada socio.
} 
Según estos datos, la expansión de la Sociedad se produjo fundamentalmente durante sus dos primeros años de vida. Aún así, la tendencia positiva, aunque moderada, continuará en 1850. Sin embargo, al año siguiente tendrán lugar los primeros síntomas de crisis. Pero será a partir de 1852 cuando esta crisis se acentúe, reflejándose en el fuerte descenso que tendrá lugar a partir de ese año ${ }^{30}$. Asimismo, de estas cifras también podemos deducir que la de Santiago, al menos numéricamente, llegó a tener una cierta importancia dentro del ámbito nacional. Más aún si tenemos en cuenta que la comisión de Santiago sólo abarcaba una parte del territorio de la diócesis, puesto que también existía una comisión en A Coruña y otra más en Betanzos $^{31}$.

Para seguir la evolución económica, contamos con las memorias de ingresos y gastos, elaboradas tanto anualmente como por semestres. En un intento de obtener una información lo más completa y precisa posible, ofreceremos los datos de ambas. Para ello, comenzaremos con las síntesis de ingresos y gastos elaboradas cada seis meses:

$\begin{array}{lccc}\text { PERÍODOS } & \text { INGRESOS }^{32} & \text { GASTOS } & \text { SALDO } \\ \text { Enero-Junio 1848 } & 15.692 & 4.141 & 11.551 \\ \text { Noviembre 1850-Abril 1851 } & 21.296 & 7.321 & 13.975 \\ \text { Mayo-Octubre 1851 } & 14.535 & 7.975 & 6.560 \\ \text { Noviembre 1851-Abril 1852 } & 12.692 & 8.364 & 4.328 \\ \text { Mayo-Octubre 1852 } & 8.456 & 5.664 & 2.792 \\ \text { Mayo-Octubre 1854 } & 6.635 & 1.616 & 5.019 \\ \text { Mayo-Octubre 1855 } & 8.030 & 1.510 & 6.520 \\ \text { Noviembre 1855-Abril 1856 } & 7.908 & 1.379 & 6.529\end{array}$

A continuación, vemos los datos por años completos:

$\begin{array}{lccr}\text { AÑO } & \text { INGRESOS } & \text { GASTOS } & \text { SALDO } \\ 1849 & 48.517 & 30.396 & 18.121 \\ 1850 & 18.644 & 18.439 & 205 \\ 1854 & 9.296 & 3.164 & 6.132 \\ 1855 & 15.938 & 2.889 & 13.049\end{array}$

\footnotetext{
${ }^{30}$ Lo que apenas variará, al menos desde 1847, serán los porcentajes de acciones por socio.

${ }^{31}$ Recordemos que en 1849 había una media de 148 socios por comisión. La de Santiago, con 267 socios, estaría muy por encima de esta media.

${ }^{32}$ Estas cifras, como no podía ser menos en el momento que nos ocupa, vienen expresadas en reales.
} 
Por su parte, los problemas y avatares que se sucedieron a lo largo del tiempo quedan mejor reflejados si analizamos detenidamente la distribución de los ingresos y los gastos. Estos serían los resultados ${ }^{33}$ :

\section{a) Ingresos}

Año 1849 Año 1850 Año 1851 Año 1852 Año 1854 Año 1855

$\begin{array}{lrrrrrr}\text { Acciones socios } & 32.480 & 18.380 & 2.300 & 440 & 110 & 0 \\ \text { Dividendos } & 0 & 0 & 0 & 9.648 & 4.641 & 3.286 \\ \text { Venta de Estatutos } & 904 & 96 & 8 & 16 & 0 & 0 \\ \text { Títulos de socios } & 1.776 & 168 & 168 & 36 & 0 & 0 \\ \text { Donaciones } & 0 & 0 & 0 & 120 & 0 & 0 \\ \text { Ayudas }^{34} & 0 & 0 & 0 & 0 & 4.000 & 0\end{array}$

\section{b) Gastos}

Año 1849 Año 1850 Año 1851 Año 1852 Año 1854 Año 1855

$\begin{array}{lrrrrrr}\text { Pensiones a socios } & 20.686 & 13.812 & 13.258 & 13.106 & 2.640 & 1.880 \\ \text { Gastos Secretaría } & 804 & 2.121 & 460 & 200 & 92 & 599 \\ \text { Escrib. y Portero }^{35} & 1.160 & 0 & 678 & 618 & 214 & 280 \\ \text { Impresiones } & 0 & 0 & 612 & 104 & 108 & 0 \\ \text { Remitido a la Junta } & 200 & 2.505 & 900 & 0 & 110 & 130\end{array}$

En cierta forma, los datos sobre la evolución económica complementan al tiempo que esclarecen los del número de socios. La Sociedad se desarrolló y marchó bien durante los dos o tres primeros años. Los ingresos por lo general superaban ampliamente los gastos. Por otra parte, las cantidades entregadas a la Junta avalan la imagen de una buena salud económica, mientras que la venta de los estatutos y títulos nos muestran una sociedad en plena expansión. Aún así, se hace necesario notar un notable descenso en el pago de acciones entre 1849 y 1850 , e igualmente

\footnotetext{
${ }^{33}$ Se hace necesario advertir que los ingresos totales de los cuadros anteriores incluyen el remanente de años pasados, los cuales no aparecen en los cuadros que se ofrecen a continuación. De ahí los desfases de las cifras entre unos y otros.

${ }^{34}$ Se trata de donaciones en el seno de la propia sociedad, producto del traslado de caudales en favor de las comisiones más necesitadas. Concretamente, los 4.000 reales que recibieron en 1854, por disposición de la Junta Directiva, procedían de la comisión de Guipúzcoa. Estas donaciones son sintomáticas del penoso estado de la comisión de Santiago. Una situación que no tenía nada que ver con años anteriores. Todavía en enero de 1852 la Junta había dictaminado que Santiago auxiliase con 2.000 reales a sus vecinos de A Coruña.

${ }^{35}$ Se trata del alquiler de la casa donde tenían su sede, los sueldos del escribiente y portero.
} 
percibimos una fuerte disminución de las pensiones ${ }^{36}$. Pero será en 1851 cuando se perciban los primeros desajustes. Los ingresos derivados del pago de las acciones caerán estrepitosamente, y en el segundo semestre de ese año se constata una fuerte reducción de los ingresos, al tiempo que los gastos se mantienen elevados. Estos problemas se acentuarán en 1852. El dinero recaudado en concepto de acciones continúa un descenso imparable, y por vez primera se hace necesario recurrir a los dividendos, que impiden el derrumbe económico de la Sociedad. Por su parte, el saldo se reduce alarmantemente, y la sociedad ya no está en condiciones de aportar dinero a la Junta. En 1854 se aprecia una brutal reducción de los gastos, impuesta, como veremos, desde la comisión. El fuerte descenso en el pago de pensiones, también relacionada, bien es cierto, con el descenso en el número de socios, es harto elocuente; también los gastos en personal de servicio. De todos modos, para sostener la situación, es imprescindible el dinero cedido, a instancias de la Junta, por la comisión de Guipúzcoa. Aparte, por supuesto, del importe de los dividendos, puesto que las cantidades recaudadas en concepto de acciones son realmente ridículas. A partir de entonces, parece que la situación se estabiliza. Los ingresos siguen siendo muy reducidos, pero los gastos disminuirán cada vez más, logrando de este modo un cierto equilibrio, tal como se refleja en la evolución positiva del saldo. De hecho, en 1855 la situación mejora significativamente respecto al año anterior, si bien ya no se registran ingresos procedentes de las acciones, sin que sepamos exactamente el por qué, quedando los ingresos entre el saldo positivo del año anterior y los dividendos.

Todos estos avatares se reflejan también en el número de pensiones adjudicadas anualmente por la comisión a sus socios enfermos o imposibilitados. Esta sería la evolución:

$\begin{array}{ccccc}\text { Año } & 1848 & - & 46 & \text { pensiones } \\ \text { “ } & 1849 & - & 74 & \text { “ } \\ \text { “ } & 1850 & - & 78 & \text { “ } \\ \text { “ } & 1854 & - & 15 & \text { “ } \\ \text { “ } & 1855 & - & 18 & \text { “ } \\ \text { “ } & 1856 & - & 4 & \text { “ }\end{array}$

\footnotetext{
${ }^{36}$ Es posible que la reducción de las cuotas como consecuencia de la reforma en los estatutos de 1849 provocara esta disminución en los ingresos por acciones. En cuanto al descenso en la percepción de pensiones, la reforma de los estatutos primero, y más adelante la decisión tomada por la Junta en diciembre de 1849, dará lugar a que, en adelante, las pensiones únicamente beneficien a los socios, no a sus familiares.
} 
De nuevo, los problemas económicos, así como la disminución del número de socios, se deducen de la fuerte reducción experimentada entre 1850 y 1854. Parece claro que, en sus últimos años, la Sociedad ya no estaba en condiciones de cumplir con los compromisos que habían dado lugar a su constitución. Los tiempos de esplendor, si es que alguna vez los hubo, habían pasado, para no volver jamás.

En cuanto a la composición interna de sus miembros, en 1.848 los socios se distribuían entre los siguientes grupos:

- Patrimonialistas

- Párrocos

- Exclaustrados

- Capellanes

- Racioneros de la Catedral

- Racioneros del Sancti Spiritus

- Canónigos de la Catedral

- Canónigos de Colegiatas

- Sochantre de la Catedral

$$
\begin{array}{lrr}
- & 100 & \left(46^{\prime} 94 \%\right) \\
- & 56 & \left(26^{\prime} 29 \%\right) \\
- & 46 & \left(21^{\prime} 59 \%\right) \\
- & 4 & \left(1^{\prime} 87 \%\right) \\
- & 2 & \left(0^{\prime} 93 \%\right) \\
- & 2 & \left(0^{\prime} 93 \%\right) \\
- & 1 & \left(0^{\prime} 47 \%\right) \\
- & 1 & \left(0^{\prime} 47 \%\right) \\
- & 1 & \left(0^{\prime} 47 \%\right)
\end{array}
$$

Su estructura interna revela que sus miembros pertenecían al clero medio y bajo, aunque sin duda predominaba el bajo clero ${ }^{37}$. Resulta muy significativo el hecho de que, en una Sociedad donde en torno a la mitad de sus miembros formaban parte del clero de la ciudad del Apóstol, un grupo tan representativo como el de los canónigos tan sólo contasen con una presencia testimonial. Lejos de representar a los distintos grupos, la Sociedad agrupaba a los colectivos más desfavorecidos, sin duda los más necesitados de ayuda. Pese al ingreso en sus filas de algunos prelados y del monopolio de los principales cargos por parte del alto clero, la Sociedad se nutría en gran medida de los estratos más modestos. Lo cierto es que una asociación que agrupaba a un clero proletarizado y empobrecido podría a la larga representar un riesgo de ruptura interna dentro del clero, incluso convertirse en una plataforma reivindicativa, no sólo frente al gobierno, sino incluso frente a los propios prelados.

${ }^{37}$ Estos datos vienen a corroborar otros que hemos obtenido sobre los 32 socios creadores de los que conservamos sus títulos. La procedencia de éstos sería la siguiente:

- Patrimonialistas

- Exclaustrados

$\begin{array}{rrr}- & 13 & \left(40^{\prime} 62 \%\right) \\ - & 8 & (25 \%) \\ - & 7 & \left(21^{\prime} 87 \%\right) \\ - & 2 & \left(6^{\prime} 25 \%\right) \\ - & 1 & \left(3^{\prime} 12 \%\right) \\ - & 1 & \left(3^{\prime} 12 \%\right)\end{array}$


Por su parte, el análisis de sus edades nos muestra el mayor peso de los tramos superiores:

$\begin{array}{llrr}\text { - Menos de 30 } & - & 1 & \left(0^{\prime} 47 \%\right) \\ \text { - De 30 a 35 } & - & 20 & \left(9^{\prime} 52 \%\right) \\ \text { - De 35 a } 40 & - & 41 & \left(19^{\prime} 52 \%\right) \\ \text { - De 40 a } 45 & - & 66 & \left(31^{\prime} 42 \%\right) \\ \text { - De 45 a 50 } & - & 36 & \left(17^{\prime} 14 \%\right) \\ \text { - Más de 50 } & - & 46 & \left(21^{\prime} 90 \%\right)\end{array}$

A la luz de los testimonios que nos han llegado, si algo abundó sobremanera en esta comisión, junto con las dificultades económicas, fueron los desencuentros entre sus miembros. La reforma de los estatutos de 1849 provocó las primeras divisiones entre los socios. Unos se manifestaron a favor y otros en contra, si bien fueron más numerosos los que se declararon en contra, especialmente en lo que atañe a la eliminación de las pensiones del socio difunto. Es el caso de varios sacerdotes de Ribeira, que se oponían expresamente a la desaparición de los causahabientes y a la imposibilidad de trasladar los derechos del socio difunto a sus padres o parientes. Por su parte, los socios del distrito de San Juan de Ortoño, juntamente con su visitador, se reunieron en junta extraordinaria a fin de presentar una queja conjunta por la variación de los primitivos estatutos "vajo los cuales se han suscrito y no de otro modo". Lo mismo hicieron los del distrito de Santa María de Couso, Portas, Boiro o Castro, entre otros. En el mismo sentido, los de Merín consideran ilegal e injusta la resolución de la Junta Directiva, por cuanto ésta debió tener presente que "al agruparse casi la generalidad del clero inscribiendose en una sociedad tan benefica y reparadora de los infortunios de la desvalida clase, se propuso no solo subvenir a sus grandes necesidades, sino también ocurrir a la indigencia que por consecuencia de aquellas pudiera afectar a los causa habientes", y en consecuencia, de no ser atendidas sus demandas, abandonarán la sociedad. Por su parte, los del distrito de Noia lamentan que la Junta Directiva haya llevado a cabo la reforma por su cuenta, sin consultar ni a las comisiones auxiliares ni a sus socios. En parecidos términos se manifestaron otros muchos sacerdotes. Pero no todos opinaban lo mismo. Los de Cambados, por contra, ven la reforma ventajosa. También la aceptaron sin reparos, siguiendo el parecer de la comisión, los de los distritos de Gándara, Muros y Reyes, junto a otros.

Tampoco se percibe un interés excesivo por la Asociación, empezando por los propios miembros de la comisión, cuya conducta dejaba mucho que desear, dada la frecuencia de las renuncias. Ya en febrero de 1848, apenas creada la comisión, renunciaba a su cargo y se daba de baja como socio el presidente de la misma, D. 
Ramón Francisco Caamaño, alegando sus muchas ocupaciones ${ }^{38}$. En mayo de 1849 le tocaba el turno a su sucesor D. Evaristo Álvarez, en este caso por razones de salud; también en ese año renunciaron varios vocales. Por exceso de trabajo, en septiembre de 1850 renunciaba a su cargo el presidente D. Juan Fontenla, al que siguieron inmediatamente el vicepresidente y el vicesecretario. Pero sería en 1853 cuando tendría lugar una deserción masiva de cargos directivos; en dos meses, entre noviembre y diciembre, renunciaron el presidente D. Pedro Jesús Caneda, el vicepresidente, varios vocales, intentándolo también el secretario D. Francisco Landeira, aunque a éste último se le obligó a continuar en el cargo ${ }^{39}$. Por supuesto, abandonaban la nave cuando veían que ésta estaba a punto de hundirse. Ciertamente, se había convertido en un oficio ingrato, especialmente cuando era preciso acosar a los morosos y ser blanco, al mismo tiempo, de todo tipo de críticas y acusaciones. Estos ejemplos no contribuían precisamente a estimular a los socios a permanecer contra viento y marea en la Sociedad.

Una Sociedad de socorros mutuos difícilmente puede subsistir si tiene que estar constantemente pendiente de si sus socios cumplen o no con sus pagos. Pero no siempre se debía únicamente a la mala fe. De hecho, y la Sociedad era perfectamente consciente de esto, muchas veces el retraso en los pagos estaba motivado por el estado lastimoso por el que estaba atravesando el clero. Sin embargo, la morosidad en la comisión de Santiago alcanzaba cotas alarmantes ${ }^{40}$. Así, en julio de 1850 los miembros de la comisión manifestaron a la Junta las proporciones que alcanzaban los morosos entre los socios de su distrito. La Junta entonces decidió que a ningún socio de Santiago se le socorrería en lo sucesivo si no tenía sus pagos en regla. En abril de 1853 los socios morosos ascendían a 85, debiendo en total a la Sociedad 7.074 reales. De éstos, 33 fueron expulsados en junio de ese año, por negarse repetidamente a pagar. A estos expul-

\footnotetext{
${ }^{38}$ Aseguraba que si había aguantado hasta entonces en el cargo, se debía a su deseo de no perjudicar a la Sociedad que estaba dando sus primeros pasos, ya que si él no hubiese aceptado el cargo, existía el riesgo de que muchos socios se echasen atrás, comprometiendo la empresa. Al día siguiente de que el presidente anunciase su cese, D. Pedro Suárez escribía a la comisión para advertirles que, en caso de que concibiesen la idea de encargarle a él la presidencia interina, renunciaría a todos sus derechos como socio. Aseguraba tratarse de una decisión tomada por unas ocupaciones que le impedían hacerse cargo de la misma.

${ }^{39}$ La renuncia al cargo del secretario no fue admitida, ya que la Junta Directiva había decidido no contestar a las muchas peticiones de renuncia que le habían hecho "vista la decadencia de esta Sociedad". No obstante, lograría su libertad en noviembre de 1854.

${ }^{40}$ En ocasiones, las reclamaciones a los morosos eran mal recibidas, llegando a provocar la ira de los interpelados. Es el caso de D. Juan Manuel Negreira, quien dirigió una carta a la comisión asegurando haber recibido el oficio de ésta con sorpresa e indignación, porque habiendo sido visitador "trabaje como el que mas en beneficio de la Sociedad, y de mis hermanos visitados, ponderando a unos las ventajas que reportarian en asociarse, y a los otros el cumplimiento de los deberes de socios (...) y entre tanto si hay mal buscarle por otra parte".
} 
sados se les siguió reclamando el dinero que debían, a lo que éstos se negaron, incluso cuando se los amenazó con llevarlos ante los tribunales. La Sociedad se encontraba necesitada de fondos y necesitaba con urgencia el dinero que según ellos se les adeudaba. Finalmente, varios de estos ex-socios fueron emplazados a presentarse ante el Provisor del Arzobispado (sólo se presentó uno de ellos). Demandantes y demandado concurrieron ante el Provisor el 27 de junio de 1853, para celebrar un juicio verbal. Tras las habituales acusaciones, réplicas y contrarréplicas, el Provisor decidió suspender la resolución del juicio, con lo que puede entenderse daba la razón a los demandados. No parece que consiguiesen recuperar el dinero; antes al contrario parece que la situación iba a peor. Así, en septiembre de 1853 la comisión no pudo socorrer a los socios enfermos por falta de dinero, debido según sus miembros al elevado número de morosos que no habían pagado lo que les correspondía en concepto de dividendo. Pero los problemas continuaron. Los fondos que entraron en su tesorería en 1854 fueron tan escasos que no se pudieron cubrir todas las necesidades. Esto había provocado descontento en algunos socios, motivando que unos suspendiesen el pago de los dividendos y otros renunciasen a su condición de socios. En mayo de 1854 la comisión no pudo dar pensión alguna a ninguno de sus socios por no haber dinero. Insistentemente pidieron ayuda a la Junta. Ésta, también en apuros, les dio algo de dinero, aunque no bastaba para atender a la totalidad de los socios. Una vez más, la comisión pedía encarecidamente a los socios que pagasen sus dividendos. La difícil situación económica en que se encontraba la comisión de Santiago obligó en noviembre de 1854 a tomar nuevas medidas. Conscientes de que muchos socios no podían pagar el dividendo que les corresponde de una sola vez cada año, se acuerda que todos paguen mensualmente un real por acción en concepto de dividendo. Los socios que sean enfermos crónicos, al menos de momento, recibirán la mitad de lo que les corresponde según sus acciones. Los que dejasen de satisfacer alguna mensualidad, y en ese mes cayesen enfermos, no tendrán derecho a pensión. También se les exige que digan claramente si en lo sucesivo desean seguir perteneciendo o no a la Sociedad.

Dicha circular fue enviada a todos los socios, y sus respuestas son un testimonio importante para constatar el sentir de los socios en esos difíciles momentos. Muchos aprovecharon para exponer sus quejas, sobre todo aquellos que se encontraban enfermos y sin socorro alguno. Sin embargo, debemos decir que únicamente cinco individuos, al ser emplazados, decidieron romper con la Sociedad ${ }^{41}$.

${ }^{41}$ Alguno, como el párroco de Vilariño, D. José Hilarión Queiruga, aprovechaba su despedida para, sin pelos en la lengua, decir lo que pensaba al respecto: "como nuestra Sociedad no es aquella sociedad instalada en 1846 que ofrecía a sus individuos un porvenir venturoso; aquella sociedad a quien, por consecuencia de radicales reformas, no conoce ya la madre que la parió" desde luego se separa de ella. 
El resto continuó; muchos incluso elogiándola y solidarizándose con la difícil situación por la que atravesaba ${ }^{42}$.

De todo esto podemos deducir que la desunión y la falta de entendimiento entre los miembros de la comisión y los socios fueron más frecuentes de lo que cabría desear. Las suspicacias estaban a flor de piel y se manifestaban con demasiada frecuencia. El caso de D. Francisco González, presbítero de Santa María de Aguiones, es muy ilustrativo al respecto y evidencia otros muchos casos parecidos. En marzo de 1854 había reclamado una pensión por enfermedad y la comisión había respondido negativamente, asegurando que no había dinero para pagarle. Poco después, la comisión le escribió pidiéndole que abonase los pagos atrasados, a lo que éste airadamente contestó que "parece una burla el que se nos echen dividendos, y no se nos pague cuando estamos imposibilitados" $"$. En definitiva, la pescadilla que se muerde la cola: los socios no pagan a la Sociedad porque no reciben de ésta las prestaciones, y los miembros de la comisión no pueden dar las prestaciones debidas si los socios no pagan. Lo cierto es que difícilmente podría la Sociedad dar prestación alguna si previamente los socios no cumplen con sus obligaciones, especialmente cuando no existe otro tipo de fuentes de ingresos. Por otra parte, la difícil situación económica por la que atravesaban sus miembros les impedía, al menos a algunos (como era de esperar, unos no pueden y otros no quieren), cumplir con la Sociedad. También debía ser muy frecuente el que algunos intentaran cobrar pensiones fraudulentamente, pese al celo de la comisión ${ }^{44}$. Aunque también hubo casos

\footnotetext{
42 No obstante, el ambiente no era precisamente de optimismo. Así, D. Benito Bermúdez, párroco de Vedra, acepta las condiciones "aunque presiento que todo no vastará a precaver la estincion de semejante fundacion tanto mas sensible esto al ver otras mas antiguas y de clases de menores circunstancias que susisten, y susistiran con mas facilidad y credito".

Por su parte, D. Antonio Rey Cortés, uno de los visitadores, permanece pero con condiciones, a saber, que el socio perciba su pensión tras probar con documentos auténticos que está enfermo "pues a la verdad Jesuchristo no manda dar limosna al rico, sino al pobre"; que se cobren los dividendos a los morosos, y que a él se le dé de baja como visitador.

${ }^{43}$ En la misma línea se manifiesta D. Pedro Jesús Caneda, párroco de Sar y antiguo presidente de la comisión, quien en noviembre de 1854 aseguraba que pagaría "cuando la Sociedad recompuesta entre de lleno a pagar, y cumpla las cargas". Su condición de expresidente evidencia que las desavenencias también se daban entre los propios miembros de la comisión.

${ }^{44}$ Como ejemplo de los desvelos de la comisión en evitar cualquier tipo de fraude, podemos citar el caso de D. Ramón Alfonsín y Oca, patrimonialista de Santa Marina de Ribeira, quien en 1851 fue acusado de celebrar misa mientras estaba percibiendo la pensión. La comisión escribió el 22 de octubre al visitador del distrito pidiéndole informes al respecto. El visitador confirmó que efectivamente había celebrado varias misas, si bien es cierto que estuvo enfermo y además destinó la pensión a comprar medicinas y tomar baños. Sin embargo, su enfermedad es algo habitual, y no le impide celebrar misa, por cuya razón no se le consideraba acreedor a recibir pensión. Tras haber recibido las informaciones pertinentes, el 20 de noviembre la comisión dio cuenta de las acusaciones al interesado, dándole ocasión de defen-
} 
en que los socios enfermos no recibieron socorros puntualmente al no tener el visitador conocimiento de los mismos, especialmente aquellos que residían en parroquias apartadas y aisladas. De cualquier forma, los morosos no deben ocultar a aquellos que cumplían, en la medida de sus posibilidades, puntualmente con sus pagos, que posiblemente fuesen la mayor parte ${ }^{45}$.

No consta, que sepamos, ninguna acusación contra los miembros de la comisión por malversación de fondos; aunque no faltaron los que acusaron a la comisión de abusos y arbitrariedades en el desempeño de sus funciones ${ }^{46}$. Tampoco consta que hubiese donaciones de particulares o instituciones ${ }^{47}$. Por fin queda una pregunta en el aire ¿interesaba realmente a la jerarquía eclesiástica sostener una asociación como esta, que en cierta forma contribuía a asimilar al clero más modesto a la condición de los obreros y artesanos?.

En relación con todo esto, surge una cuestión que no queremos soslayar, ¿qué suponía realmente para la depauperada economía de los clérigos pertenecer a esta Sociedad? ¿eran las cuotas a pagar tan gravosas para ellos?. A esta pregunta intenta-

derse de las mismas. Éste, por supuesto, no desaprovechó la ocasión. El 25 de noviembre escribía al presidente de la comisión, indignado, en una carta que destaca por su tono airado. Jamás pudo esperar que entrar en la Sociedad "en vez de proporcionarme consuelos, atragera sobre mi disgustos, y tormentos, y que un chisme de un infame calumniador fuese bastante á poner en duda la veracidad de un socio. Desgracia es que entre Eclesiásticos se observe con frecuencia lo que en otras clases se vé raras veces". Asegura que durante su enfermedad no dijo misa. Lo más que hizo que dar un paseo para distraerse y cumplir con el consejo de los médicos de que hiciese ejercicio. En cuanto a una solicitud redactada en Cuntis el 29 de septiembre por la que reclamaba la pensión "ignoro si con efecto llevaba la fecha que se dice, ó si, yendo mal hechas las cifras, ha leido V.S. 29, en vez de 26 (...) pero es lo cierto que estube en Cuntis medicinándome, que la circunstancia que V.S. nota de no ir firmado el memorial indica bien a las claras el mal estado de mi salud en aquel entonces, la debilidad de mi cabeza, su desasosiego, á affecto de los baños y medicinas, y ultimamente la buena fé y ignocencia de mi proceder".

${ }^{45}$ Aunque los datos en este sentido sean escasos, hubo miembros que destacaron por su honradez y abnegación. Por ejemplo, D. Francisco Javier Fontecoba, presbítero de Santiago, percibió una pensión por enfermedad en mayo de 1851 durante 16 días, al término de los cuales, y viendo que la enfermedad se prolongaba, escribió a la comisión para notificarle su decisión de ceder en favor de la sociedad los sucesivos socorros que le pudiesen corresponder, quedando, de momento, únicamente con los beneficios espirituales.

46 de los que dejaban la Sociedad lo hacían en silencio, mientras que otros, como D. Mateo de los Dolores, sacerdote de Noia, lo hacían acusando gravemente a la Sociedad. Éste renuncia "a semejante sociedad, ni quiere jamas pertenecer a ella por la arbitrariedad con que se conculcan sus Instituciones". Asegura que le retuvieron el título de socio durante cinco o seis meses, a él y a otros clérigos de Noia, además de exigirle que pagase sus acciones antes de que su cumpliese el tiempo para ello. No fue el único caso. A otros socios también les retuvieron el título, pese a haber abonado el primer tercio de sus acciones así como los derechos de expedición. De hecho, la comisión fue reprendida por la Junta Directiva por este motivo en 1850.

${ }^{47}$ De hecho, únicamente tenemos constancia de una donación que en 1852, y por disposición de la Junta Directiva, hizo D. Juan Ramón Rey, por un importe de 120 reales. 
remos dar una respuesta adecuada. Obviando los circunstancias personales de cada individuo, lo cierto es que dependía tanto del sueldo o rentas que percibieran (lo que está en relación directa con el grupo al que pertenecían) como de las edades que tuvieran, además de la cuantía de la pensión que deseasen percibir. Pero, sobre todo, el haber sabido entrar en el momento oportuno. Tomemos como referente una cuota de tres acciones, que daba lugar a una modesta pensión de 6 reales por día ${ }^{48}$. Igualmente, centremos nuestra atención en los grupos de edad más numerosos. Estas serían las cantidades a pagar anualmente, antes y después de la reforma de los estatutos:

$\begin{array}{llcccc}\text { - Entre 35-40 } & - & 160 & (1846) & / & 100 \\ \text { - Entre 40-45 } & - & 300 & & / & 150 \\ \text { - Entre 45-50 } & - & 480 & & / & 150 \\ \text { - Más de 50 } & - & - & & / & 300\end{array}$

Ahora veamos la situación de los distintos grupos. Así, por ejemplo, los exclaustrados percibían como asignación del gobierno una media de 1.825 reales anuales ${ }^{49}$. Para aquellos que no tuviesen ningún otro ingreso complementario, y considerando que la media de edad de este colectivo era muy alta, en torno a los 55 años en 1845 , pertenecer a la Sociedad podría suponer el $16^{\prime} 4 \%$ de su sueldo ${ }^{50}$. Luego están los párrocos. Los de Santiago percibían una media de 6.428 reales al año. También tenían una edad elevada, que sobrepasaba los 55 años. En ese caso, las cantidades a pagar supondrían el 4`66 \% en 1849, o incluso el 7`46 \% en 1846, de estar entre los 45 y 50 años. Mucho más modesto era el sueldo de los coadjutores, 2.500 reales. Sin embargo, su media de edad apenas rebasaba los 35 años. En este caso, el porcentaje sería del 6`4\% y del $4 \%$ en 1846 y 1849. Pero también señalamos la importancia de ingresar oportunamente. Para los socios fundadores, y en la comisión de Santiago tenían esta condición la mayor parte, la cantidad a pagar por tres acciones era de 60 reales anuales, cualquiera que fuese la edad ${ }^{51}$. Pero también debemos tener en cuenta la existencia de los dividendos, que se sumaban a las cuotas ${ }^{52}$. De hecho, los dividendos se habían convertido en el caballo de batalla a la hora de pagar.

\footnotetext{
${ }^{48}$ Una cuota que, por otra parte, y como ya hemos visto, está por debajo de la media.

${ }^{49}$ Datos tomados de mi Tesis Doctoral El clero compostelano en el siglo XIX, pp. 663-665.

${ }^{50} \mathrm{~A}$ partir de 1849 . Antes no tendrían cabida, a no ser como socios fundadores. Para aquellos cuya edad estuviese entre 45 y 50, la entrada en la Sociedad antes de la reforma supondría el 26׳3 \% de su asignación.

${ }^{51}$ En este caso, los costes se reducen notablemente. Para los exclaustrados sería el 3`28 \% de su paga; el 0`93\% para los párrocos compostelanos, y para los coadjutores el $2^{`} 4 \%$.

52 Para los socios que tuvieran estas tres acciones, la cantidad a pagar como dividendo, desde enero hasta abril de 1852, fue de 144 reales anuales (4 reales mensuales por acción). Desde abril de ese año, se acordó un dividendo de un real mensual (36 reales al año). En 1854 volvió a acordarse la misma cantidad.
} 
En suma, las cantidades a pagar no eran en modo alguno exorbitantes; antes al contrario se trataba de unas cuotas bastante modestas. De hecho, eran incluso más bajas que las de algunas sociedades de socorros mutuos instaladas en Santiago ${ }^{53}$. Aunque, por supuesto, la condición de los socios fundadores resulta difícilmente equiparable a la de los demás. La cuestión de si eran asequibles o no resulta más compleja. Dependería de si su paga era puramente de subsistencia o permitía la existencia de un, siquiera mínimo, excedente. En este sentido, exclaustrados y patrimonialistas serían sin duda los más desfavorecidos. Al final, sobre la duda de si la morosidad en los pagos era voluntaria o forzada, tendremos que concluir con una diversidad de situaciones, como diversa era también la estructura interna del clero; y en todo caso, a falta de datos concluyentes, tendrá que quedar relegada al ámbito de la conciencia de cada cual.

\section{APÉNDICES}

\section{1 - EVOLUCIÓN DE LOS INGRESOS Y GASTOS}

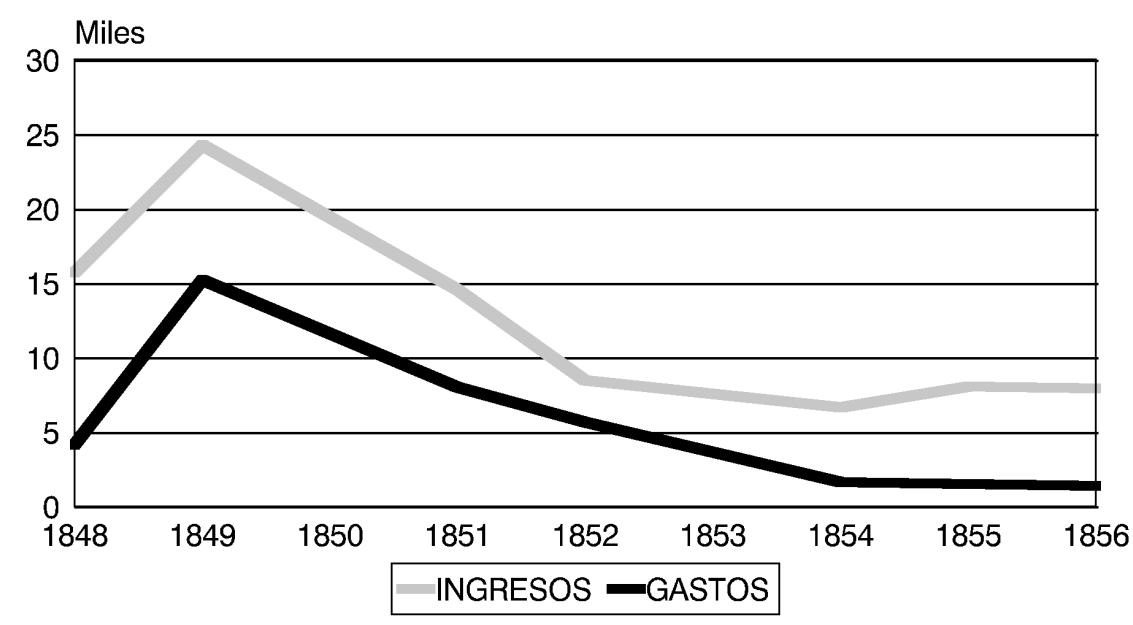

${ }^{53}$ Las demás sociedades de socorros mutuos suponían para los socios unas cuotas anuales de 72 o 48 reales, dependiendo de la sociedad de que se tratase, a las que había que añadir unas cuotas de entrada por un importe de 50 a 150 reales para aquellos que estuviesen entre los 40 y 50 años, y de 200 reales para los mayores de 50. Esto les daba derecho a 4 reales diarios en caso de enfermedad (Herminia Pernas Oroza, $O p$. Cit.). Pues bien, para recibir las mismas prestaciones (4 reales), un socio fundador (y recordemos que en Santiago lo eran la mayoría) de la sociedad del clero debía pagar 40 reales anuales, sin cuota de entrada de ningún tipo, aunque, eso sí, con dividendos. Por otra parte, debemos tener en cuenta que la mayor parte de los miembros de estas asociaciones eran obreros con un modesto jornal. 


\section{2 - DISTRIBUCIÓN DE LOS INGRESOS}

A) Año 1849

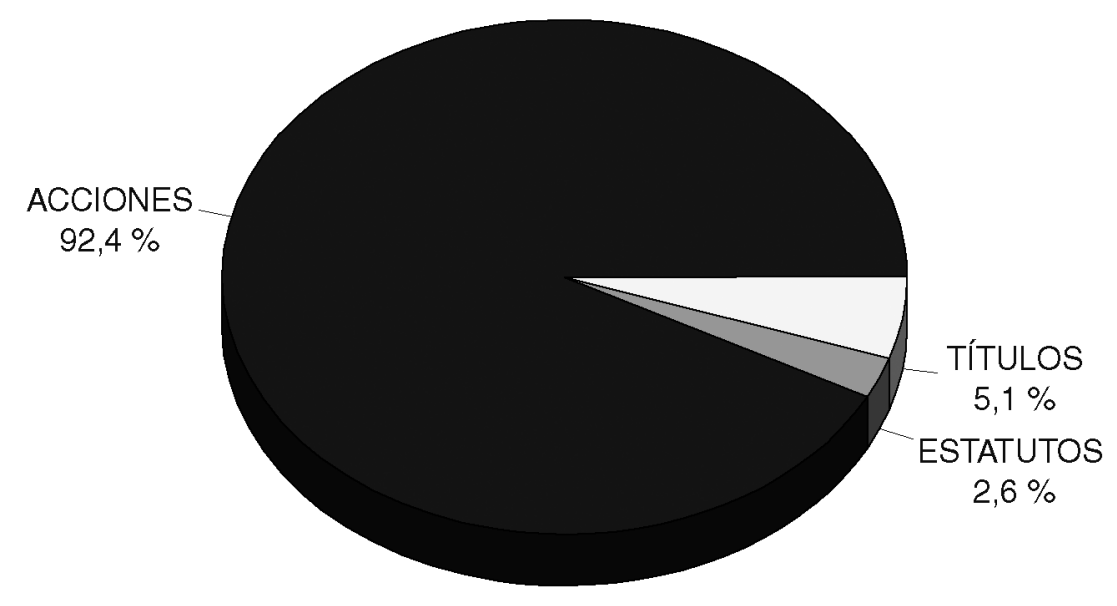

B) Año 1850

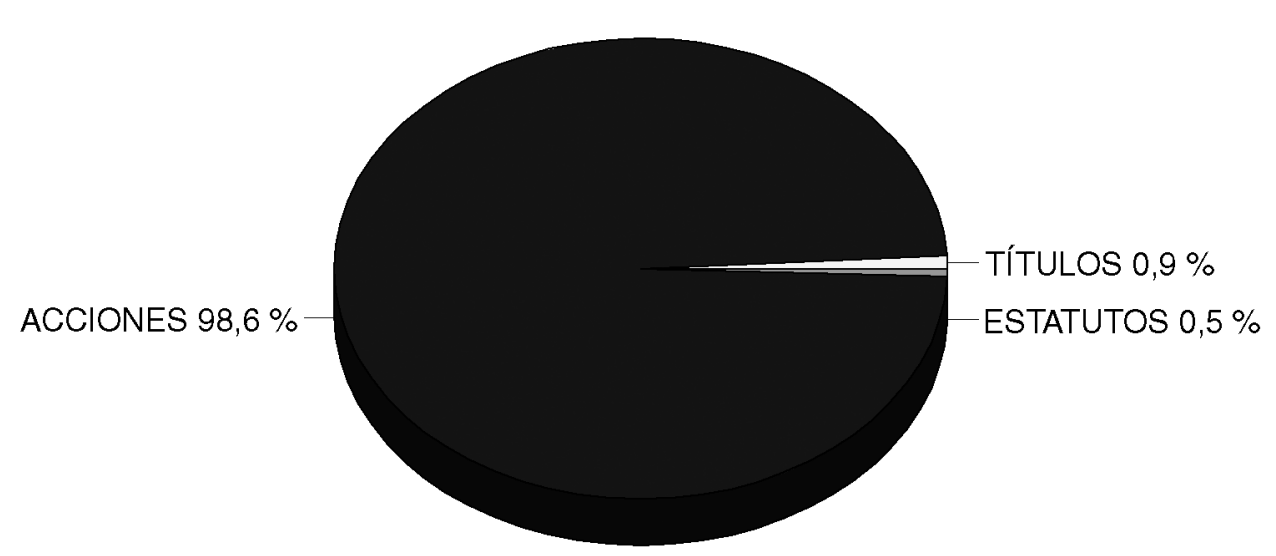


C) Año 1852

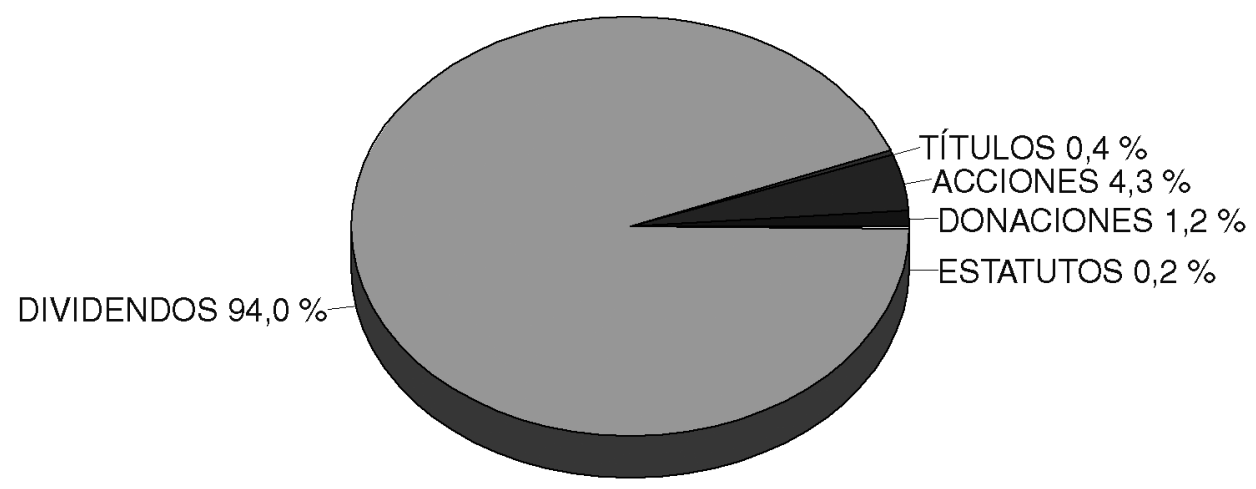

D) Año 1854

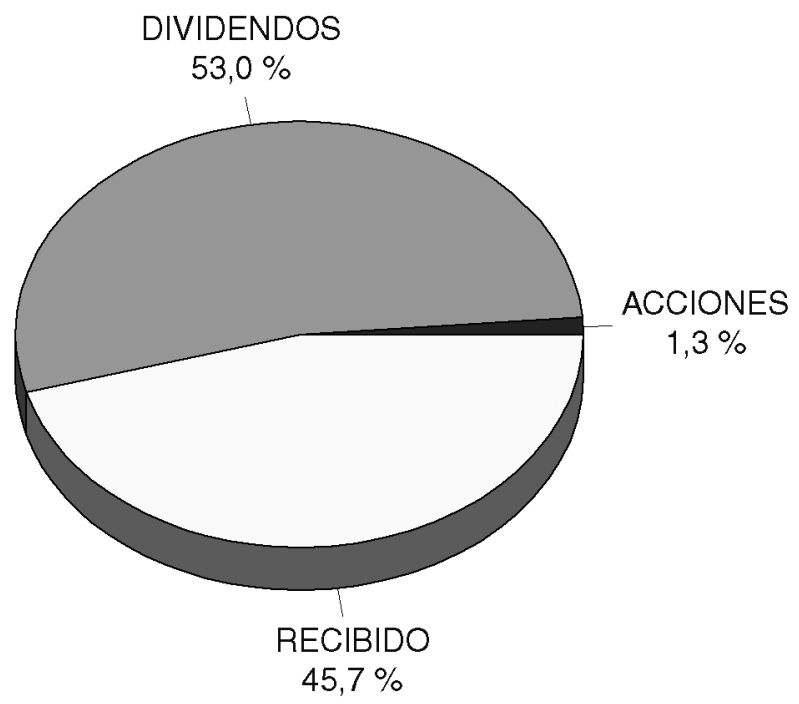

